Kishore, A. K. et al. (2018) Microbiological etiologies of pneumonia complicating stroke: a systematic review. Stroke, 49(7), pp. 1602-1609.

(doi: 10.1161/STROKEAHA.117.020250)

There may be differences between this version and the published version. You are advised to consult the publisher's version if you wish to cite from it.

http://eprints.gla.ac.uk/164710/

Deposited on: 28 November 2019

Enlighten - Research publications by members of the University of Glasgow http://eprints.gla.ac.uk 


\section{Microbiological etiologies of pneumonia complicating stroke: A systematic review}

Amit K Kishore ${ }^{1,2}$ FRCP, Andy Vail ${ }^{3}$ MSc, Adam R Jeans ${ }^{4} \mathrm{MD}$, Angel Chamorro ${ }^{5} \mathrm{PhD}$, Mario Di Napoli ${ }^{6} \mathrm{MD}$, Lalit Kalra ${ }^{7} \mathrm{PhD}$, Peter Langhorne ${ }^{8} \mathrm{PhD}$, Christine Roffe ${ }^{9} \mathrm{MD}$, Willeke Westendorp ${ }^{10} \mathrm{MD}$, Paul J Nederkoorn ${ }^{10} \mathrm{PhD}$, Javier Garau ${ }^{11} \mathrm{PhD}$, Diederik van de Beek ${ }^{10} \mathrm{PhD}$, Joan Montaner ${ }^{12,13} \mathrm{PhD}$, Mark Woodhead ${ }^{14} \mathrm{DM}$, Andreas Meisel ${ }^{15} \mathrm{MD}$, Craig J Smith ${ }^{1} \mathrm{MD}$, on behalf of Pneumonia In Stroke ConsEnsuS (PISCES) Group.

${ }^{1}$ Greater Manchester Comprehensive Stroke Centre, Manchester Academic Health Science Centre, Salford Royal Foundation Trust, UK; ${ }^{2}$ Division of Cardiovascular Sciences, University of Manchester, Manchester, UK; ${ }^{3}$ Centre for Biostatistics, University of Manchester, Salford Royal Foundation Trust, UK; ${ }^{4}$ Department of Microbiology, Salford Royal NHS Foundation Trust; ${ }^{5}$ Comprehensive Stroke Center, Department of Neuroscience, Hospital Clinic, University of Barcelona, Barcelona, Spain; ${ }^{6}$ Neurological Service and Stroke Unit, San Camillo de' Lellis General Hospital, Rieti, Italy; ${ }^{7}$ Clinical Neurosciences, King's College Hospital NHS Foundation Trust London, UK; ${ }^{8}$ Institute of Cardiovascular and Medical Sciences, University of Glasgow, Glasgow Royal Infirmary, Glasgow, UK; ${ }^{9}$ Keele University Institute for Science and Technology in Medicine, Guy Hilton Research Centre, Stoke-on-Trent, UK; ${ }^{10}$ Department of Neurology, Academic Medical Center, Amsterdam Neuroscience, University of Amsterdam, Amsterdam, Netherlands; ${ }^{11}$ Department of Medicine, Hospital Universitari Mutua de Terrassa, Barcelona, Spain; ${ }^{12}$ Neurovascular Research Lab, Vall d'Hebron Research Institute, Barcelona, Spain; ${ }^{13}$ Institute de Biomedicine of Seville, IBiS/Hospital Universitario Virgen del Rocío, University of Seville, Seville, Spain; ${ }^{14}$ Faculty of Medical and Human Sciences, University of Manchester \& Department of Respiratory Medicine, Manchester University NHS Foundation Trust, Manchester Academic Health Science Centre, Manchester, UK; ${ }^{15}$ NeuroCure Clinical Research Center, Center for Stroke Research Berlin Department of Neurology Charité Universitaetsmedizin Berlin, Germany

Cover title: Bacterial etiology of post-stroke pneumonia Corresponding author: Dr Amit K Kishore 
Greater Manchester Neurosciences Centre, Salford Royal NHS Foundation Trust, Stott lane, Salford, M6 8HD, UK;

Tel: +441612064044

Amit.Kishore@manchester.ac.uk

Word count: 5273

\section{Itemized list of Tables and Figures}

Table 1: Study characteristics

Table 2: Frequency of isolated organisms in pneumonia complicating stroke in comparison to other forms of pneumonia

Figure 1: Flow diagram of systematic search methodology

Figure 2: Forest plot of pneumonia frequency according to stroke subtype

Fig 3: Proportion of studies identifying the eight most commonly isolated organisms

Online only Table I: Search Terms

Online only Table II: Eligibility criteria

Online only Table III: Patient characteristics

Online only table IV: The eight most commonly isolated organisms in positive cultures (\%) in the included studies

Online Only Table V: Definition of pneumonia terminologies

Online only Figure I: Funnel plot

Key words: stroke, pneumonia, infection, bacteria, systematic review 


\begin{abstract}

\section{Background and Purpose}

Identifying the causal pathogens of pneumonia complicating stroke is challenging and antibiotics used are often broad spectrum, without recourse to the microbiological etiology. We aimed to review existing literature to identify organisms responsible for pneumonia complicating stroke, prior to developing a consensus based approach to antibiotic treatment.
\end{abstract}

\title{
Methods
}

A systematic literature review of multiple electronic databases using pre-defined search criteria was undertaken, in accordance with Cochrane and PRISMA guidance. Published studies of hospitalized adults with ischemic stroke (IS), intracerebral hemorrhage (ICH), or both, which identified microbiological etiologies for pneumonia complicating stroke up to $1^{\text {st }}$ January 2017, were considered. Analysis included summary statistics and random-effects meta-analysis where appropriate.

\section{Results}

15 studies (40\% IS, 60\% IS and ICH) involving 7968 patients were included. Reported occurrence of pneumonia varied considerably between studies (2\% to $63 \%)$ with a pooled frequency of $23 \%$ (95\% Confidence Interval, $14 \%-34 \% ; \mathrm{I}^{2}=99 \%$ ). Where reported $(60 \%)$, the majority of pneumonia occurred within 1 week of stroke (78\%). Reported frequency of positive culture data ( $15 \%$ to $88 \%$ ) varied widely. When isolated, aerobic Gram negative bacilli (AGNB, 38\%) and Gram positive cocci (GPC, 16\%) were most frequently cultured; commonly isolated organisms included Enterobacteriaceae (21.8\%: Klebsiella pneumoniae, $12.8 \%$ and Escherichia coli, 9\%), Staphylococcus aureus (10.1\%), Pseudomonas aeruginosa (6\%), Acinetobater baumanii (4.6\%) and Streptococcus pneumoniae (3.5\%). Sputum was most commonly used to identify pathogens, in isolation (40\%) or in conjunction with tracheal aspirate $(15 \%)$ or blood culture $(20 \%)$. 


\section{Conclusions}

Whilst analysis was limited by small and heterogeneous study populations, limiting determination of microbiological causality, this review suggests AGNB and GPC are frequently associated with pneumonia complicating stroke. This supports the need for appropriately designed studies to determine microbial etiology and a consensus based approach in antibiotic usage and further targeted antibiotic treatment trials for enhanced antibiotic stewardship. 


\section{Introduction}

Pneumonia complicating stroke occurs frequently, independently increasing mortality 3 -fold and increasing hospitalisation costs, length of stay and likelihood of poor outcome in survivors. ${ }^{1,2}$ While diagnosis remains challenging, the Pneumonia In Stroke ConsEnSus (PISCES) group recommended that "Stroke-Associated Pneumonia" (SAP) was the preferred diagnostic terminology covering the spectrum of lower respiratory tract infections complicating stroke within the first week and hospital acquired pneumonia (HAP) after 1 week. ${ }^{3}$ Further, acknowledging the limitations of current biomarkers and accessibility of microbiological samples, modified Centers for Disease Control and Prevention (CDC) criteria were proposed to aid clinicians and researchers in diagnosing SAP in non-ventilated patients. ${ }^{3}$

Once SAP is suspected or diagnosed, however, use of antimicrobials vary and are either clinician dependant or guided by local policy for community acquired pneumonia (CAP) or HAP. ${ }^{4}$ Antibiotics used are often broad spectrum, without recourse to the microbiological etiology. The ability to better inform choice of antibiotic therapy in SAP, based on defined or likely microbial etiology, might lead to improved outcomes and enhanced antibiotic stewardship. Identifying microbiological etiology in non-ventilated stroke patients is challenging, due to the difficulties in obtaining direct samples from the lower respiratory tract (impaired cough and limited expectoration) and lack of applicable invasive procedures such as bronchoscopy in conscious stroke patients, in addition to reliance on sputum samples with the inherent risk of contamination from oropharyngeal commensal organisms. ${ }^{5}$ While bacterial colonisation of the oropharynx could potentially limit interpretation of positive sputum samples, poor diagnostic sensitivity of microbiological culture methods such as blood culture specimens (positive in $<10 \%)^{6}$ and pleural fluid aspirate limit their use. Most importantly, prior use of antibiotics hampers the sensitivity of microbiological techniques and 
current stroke guidelines do not recommend early nonselective preventive antibiotic treatment. ${ }^{7,8}$ As part of the ongoing PISCES collaboration, we sought to identify microbiological etiologies for pneumonia complicating stroke through a systematic review of available literature to help inform a planned consensus based approach for antibiotic treatment. 


\section{Methods}

A systematic literature review was undertaken in accordance with the Preferred Reporting Items for Systematic Reviews and Meta-Analyses (PRISMA) statement and Cochrane guidance. ${ }^{9,10}$ The authors declare that all supporting data are available within the article [and its online supplementary files].

\section{Data sources and searches}

Searches were undertaken in MEDLINE (NIHL interface, $1946-1^{\text {st }}$ January 2017), EMBASE (NIHL interface, 1947-1 ${ }^{\text {st }}$ January 2017) and Cochrane Central Register of Controlled Trials (Wiley interface, current issue) using pre-defined search criteria and terms (Online only

Table I). Hand searching of reference lists for additional eligible articles was also carried out, and the members of PISCES group were invited to provide any other potentially eligible articles. Non-English full-text articles were translated and considered for inclusion if eligibility criteria were met.

\section{Study selection}

Published studies of hospitalized adults with ischemic stroke, intracerebral hemorrhage (ICH), or both, which identified any potential pathogen responsible for pneumonia complicating stroke, or which had used objective criteria for diagnosing pneumonia complicating stroke (but not reported causative organisms) were independently screened for eligibility by two reviewers (AKK and CJS), using the study title and abstract (Online Only Table II). For those studies which used objective criteria for pneumonia but which hadn't reported causative pathogens, corresponding authors were contacted by e-mail for unpublished information on pathogens responsible for pneumonia if available. Lead or corresponding authors of studies under consideration were also contacted by e-mail to resolve any issues relating to assessment of eligibility or data extraction. Discrepancies relating to 
eligibility or data extraction were resolved by a consensus discussion between the same two study investigators. 


\section{Data Extraction}

Data were independently extracted by two reviewers (AKK and AV) and included study design, sample size, publication status and demographical data (year of study, country of study, clinical environment), stroke type (ischemic, ICH or both), interval from admission to diagnosis of pneumonia, frequency of pneumonia, criteria used for pneumonia diagnosis, mean age, mean National Institutes of Health Stroke Scale (NIHSS) score, cardiovascular risk profile, swallow screening, proportion of nil oral/tube-fed, type of culture specimen (sputum, blood culture, pleural or tracheal aspirate, serology), organisms identified and antibiotic usage (prophylactic and/or treatment). Reported data in the identified eligible publications were supplemented by contacting corresponding or lead authors where necessary.

\section{Study Outcomes}

The primary outcomes were the frequencies of the most commonly isolated microbial species among the included studies and the proportion of these organisms responsible for pneumonia. Secondary outcomes included: (1) The frequency of positive microbiological cultures and proportions of isolated organisms in positive cultures; (2) Relationships between microbial species and time interval from stroke onset to pneumonia; (3) Frequency of identified pathogens across different geographical regions.

\section{Risk of Bias and Quality Assessment}

We anticipated inclusion of both randomized controlled trials (RCTs) and non-randomized studies that had pneumonia as an outcome but were not primarily designed to identify microbiological etiologies. Hence, a formal statistical tool for assessing bias or the individual quality of the studies was not used as we were less concerned about the design or the effects 
of interventions used in the individual studies for this review. However, as cultures for organisms would only be undertaken when pneumonia is suspected or diagnosed, heterogeneity among studies reporting pneumonia was assessed using random-effects model. Heterogeneity was quantified with the $\mathrm{I}^{2}$ statistic as reported in a previous study ${ }^{1}$. This measures the proportion of variation ascribed to excess heterogeneity beyond that anticipated by chance. Because of anticipated heterogeneity between studies reporting pneumonia, further quantitative meta-analysis on bacterial etiology was not undertaken. Summary statistics were instead undertaken to describe primary and secondary outcomes. A post-hoc, descriptive comparison of the frequency of pathogen species detected in pneumonia complicating stroke with other forms of pneumonia (e.g. CAP, HAP) was also undertaken. 


\section{Results}

\section{Search Results}

A total of 6231 unique publications were identified by electronic searches and through the PISCES collaborators (Figure 1).Fifteen fully published studies were finally considered eligible for inclusion. ${ }^{11-25}$

\section{Study and patient characteristics (Table 1, Online only Table III)}

The studies included retrospective $(40 \%)$ or prospective $(33 \%)$ observational studies and randomised trials (27\%). 54\% were European or North American studies; $46 \%$ were performed in South East Asia or Asia Pacific region. The majority of the studies were conducted on the acute stroke unit $(72 \%)$. Other clinical environments included rehabilitation wards $(7.5 \%)$ and intensive care units $(15 \%)$. The mean age of the patients in individual studies ranged from 58 to 83 years. Baseline stroke severity (NIHSS) was reported in only $73 \%$ of studies, with a mean ranging from 5 to 19 . Three studies were RCTs of prophylactic

antibiotics. ${ }^{11,15,25}$ Two studies were exclusively in nasogastric (NG) or percutaneous endoscopic gastrostomy (PEG) tube fed participants. ${ }^{21,23} 33 \%$ of the studies included mechanically ventilated patients. Entry criteria to the studies varied widely, with only 1 study having the identification of microbiological etiology for pneumonia complicating stroke as a primary objective ${ }^{12} ; 2$ studies excluded patients on immunosuppressive medication, with prior malignancy, or other forms of immunosuppression prior to stroke. ${ }^{11,22}$ Other comorbidities and cardiovascular risk factor profiles were reported varyingly (Online only Table III).

Diagnosis and frequency of pneumonia 
Reported occurrence of pneumonia varied between studies (2\% to 63\%). Pooled frequency of reported pneumonia was $23 \%$ (95\% CI 14\%-34\%; $\mathrm{I}^{2}=99 \%$, Figure 2). Substantial heterogeneity was noted even when adjusted to stroke subtype (ischemic stroke, $\mathrm{I}^{2}=96 \%$; mixed ischemic stroke and $\mathrm{ICH}, \mathrm{I}^{2}=99 \%$ ) or geographical location (Asian studies, $\mathrm{I}^{2}=97.4 \%$ and European or North American studies, $\left.\mathrm{I}^{2}=97.8 \%\right)$. When reported $(60 \%)$, the majority of pneumonia occurred within 1 week of stroke (78\%). The Centers for Disease Control and Prevention (CDC) criteria (45\%) and ad hoc objective criteria (40\%) were the most commonly used objective criteria to diagnose pneumonia.

\section{Microbiological etiology}

Sputum culture was most commonly used to identify pathogens either in isolation (40\%), or in conjunction with tracheal aspirate $(15 \%)$, and blood culture (20\%). Reported frequency of positive culture data ( $15 \%$ to $88 \%$ ) varied considerably. Only 3 studies described the culture methods used to identify organisms. ${ }^{4,13,25}$ No bacterial growths were reported in 2 studies $(15 \%$ and $67 \%) .{ }^{12,25}$ Identification of bacterial species in positive cultures varied between studies (Online only table IV). No pathogen was identified in every study, although Staphylococcus aureus was identified in positive cultures in 14 of 15 (93\%) studies whilst Acinetobacter baumanii was identified in positive cultures in only 6 of 15 (40\%) studies (Online only Table IV and Figure 3). Antibiotic susceptibility was not reported in the majority of studies; no studies reported any viral or other atypical organisms, although it was unclear if these were tested for.

The proportions of microbial species associated with pneumonia also varied between studies. Overall, aerobic gram negative bacilli (AGNB, 38\%) and gram positive cocci (GPC, 16\%) were most frequently responsible for pneumonia; commonly isolated phenotypes (Table 2) included Enterobacteriaceae (21.8\%: Klebsiella pneumoniae, $12.8 \%$ and Escherichia coli, 
9\%), S. aureus (10.1\%), Pseudomonas aeruginosa (6\%), Acinetobater baumanii (4.6\%) and Streptococcus pneumoniae (3.5\%). Studies that included patients at relatively higher-risk of pneumonia i.e. exclusively dysphagic patients or intensive care studies ${ }^{15,17,19,21}$ were found to have a high proportion of AGNB and S. aureus, in comparison to lower risk studies (unselected stroke patients with $\leq 15 \% \mathrm{ICH}$ and/or mean NIHSS $\leq 5$, Table 1 ). It was not possible to explore relationships between timing of pneumonia or it's severity with individual organisms because of insufficient data.

We compared the frequencies of the 8 most commonly identified organisms in pneumonia complicating stroke with those of hospitalised CAP, VAP and HAP (Table 2) from recent reviews of literature (terminologies defined in Online only Table V). ${ }^{26,27,28,29}$ Geographical variations in bacterial etiology were observed in our study as seen as in the other reviews. In particular, gram-negative opportunistic pathogens such as $P$. aeruginosa and A. baumanii were more commonly isolated in South Asia or Asia Pacific regions (75\% \&100\%) as opposed to Western Europe or the USA (28\% \& 0\%). Several organisms were reported with comparable frequency (range) to VAP or HAP (e.g. K. pneumoniae, E. coli). S. pneumoniae, the organism most frequently identified in CAP, was detected less often in pneumonia complicating stroke. The organisms most often reported in HAP and VAP ( $S$. aureus and $P$. aeruginosa) were also identified less frequently in pneumonia complicating stroke.

\section{Antibiotic usage}

Only 4 studies (24\%) identified antibiotics used to treat pneumonia complicating stroke. ${ }^{13,15,20,25}$ The antibiotic of choice was determined by local hospital policy and commonly included $\beta$-lactam (including ureidopenicillin and $2^{\text {nd }} / 3^{\text {rd }}$ generation cephalosporins) antibiotics $+/-\beta$ lactamase inhibitors and $2^{\text {nd }} / 3^{\text {rd }}$ generation fluoroquinolones and was always initiated prior to obtaining antibiotic sensitivities. Only 1 study reported the 
proportion of patients with pneumonia receiving antibiotics, the number of pneumonia episodes and functional outcomes following treatment with antibiotics. ${ }^{25}$

\section{Discussion}

Pneumonia occurs most frequently during the first week after stroke (SAP) ${ }^{1,3}$ and may therefore include microbiological etiologies associated with hospitalized CAP or HAP. Our study suggests that AGNB (e.g. K. pneumoniae, E. coli and P. aeruginosa) and GPC (e.g. S. aureus and S. pneumoniae) were associated with the majority of pneumonia complicating stroke when cultures were sent. A recent review suggested that close to $80 \%$ of hospitalized CAP were caused by S. pneumoniae, Mycoplasma pneumoniae, Chlamydia pneumoniae and H. influenza. ${ }^{26}$ The same review found that approximately $50 \%$ of HAP was caused by $S$. aureus and $35 \%$ by Pseudomonas species, Klebsiella species, Escherichia species, Acinetobacter species and Enterobacter species. ${ }^{26}$ The spectrum of identified organisms in our study appear to be more closely related to HAP than ventilator-associated pneumonia (VAP) or hospitalised CAP, although antibiotic susceptibilities were not reported in most of the included studies. Further, none of the included studies reported the results of investigations for viral or atypical pathogens, or even if they were done. Whilst our study is a comprehensive systematic literature research and collaboration within the PISCES group, our findings need to be interpreted with caution due to several inherent limitations.

First, there was marked heterogeneity between the included studies, which likely contributed to the variation in identified organisms and their relative contributions to pneumonia. For example, studies undertaken in the critical care environment might yield a higher proportion of organisms overall because of access to more direct sampling (e.g. bronchoscopy or tracheal aspirate) and also more frequent etiologies due to organisms typical of HAP or VAP. 
We could not identify any single factor that fully explained the high heterogeneity $\left(\mathrm{I}^{2}=99 \%\right)$. Although both stroke type and our prospective risk categorisation (Table 2) showed anticipated differences in pneumonia frequency, even within our 'very high risk' category frequency ranged from $14 \%$ to $63 \%$ (Figure 2), and heterogeneity remained extremely high $\left(\mathrm{I}^{2}>90 \%\right)$ within each risk category. The asymmetry of the scatterplots seen in the funnel plot also reflects the high heterogeneity among studies which was not corrected even when subgroup analysis was undertaken with pneumonia risk stratification (Online only Figure I). $66 \%$ of the included studies in our review were deemed high or very high risk (Table I) for developing pneumonia reflecting the higher frequency of pneumonia seen in this review as opposed to a previous systematic review. ${ }^{1}$ Apart from patient selection, the overall high heterogeneity also reflects varying geographical location, different study designs, inclusion criteria, timing from stroke onset to sampling, and differences in standardised outcome definition for SAP. We were unable to differentiate pneumonia and causative pathogens for patients admitted from institutional environments such as nursing homes, which may have also contributed to heterogeneity. Stroke registries, not routinely expected to collect and maintain data on microbiological etiology, were also excluded unless specific mention was made regarding determining bacterial etiology, which could have contributed to selection bias and heterogeneity. The variation in approach to diagnosis of pneumonia complicating stroke is well-recognised, ${ }^{1}$ and may therefore influence the threshold for sending microbiological samples, contributing to verification bias. Second, only one of the studies was primarily designed to identify the microbial etiology of pneumonia complicating stroke, ${ }^{12}$ whilst the remaining studies collected microbiological data when available within the context of their individual study objectives. It is reasonable to assume that the proportion of positive cultures could be higher if culture samples were sent systematically in all suspected cases of pneumonia. However, compared to other clinical settings (e.g. CAP or 
VAP), consistently obtaining sputum samples in non-ventilated stroke patients is challenging and alternative strategies (e.g. bronchoscopy for VAP) are limited. Third, it was unclear amongst most studies as to when culture samples were sent in relation to onset of stroke and suspicion or diagnosis of pneumonia. Although the majority of pneumonia in our review occurred within a week of stroke symptom onset, it was not possible to further explore microbiological etiologies in relation to timing of pneumonia relative to stroke symptom onset. Whilst one could hypothesise that organisms commonly associated with CAP are most likely causal in early SAP ( $\leq 72$ hours), and those associated with HAP causal in SAP beyond $72 \mathrm{~h}$, we were unable to confirm or refute this finding because of limited data in the individual studies. Our observations of an apparent low yield of CAP organisms, and higher yield of HAP organisms could be at least in part due to sampling bias beyond $48-72 \mathrm{~h}$ after stroke onset. Fourth, microbiological methods used to collect sputum samples, number of specimens sent when pneumonia was diagnosed, delays in analysing samples if any, and laboratory techniques used were inadequately reported. None of the studies used modern molecular based polymerase chain reaction (PCR) methods or urinary antigen testing (for organisms such as S. pneumoniae and Legionella pneumophilia).This may also contribute to differences in the observed frequencies of positive culture data and the apparent lack of atypical or viral etiologies. Interestingly, a recent study reviewing hospitalised patients identified close to $22 \%$ of CAP inpatients had viral pathogens (most commonly rhinovirus, $9 \%$ and influenza, $6 \%$ ) implying that a viral etiology of SAP in at least some individuals may be possible. ${ }^{30}$ Finally, antibiotics preceding index stroke (especially for patients with chronic lung disease) may have influenced microbiological cultures. For example, in the PANTHERIS study, when sputum samples were analysed, $36 \%$ of samples were positive for organisms in the placebo group as opposed to $9 \%$ in the prophylactic antibiotic group. ${ }^{15}$ While the numbers are too 
small to form further conclusions, prophylactic antibiotics administered to the participating stroke patients in the 3 RCTs may have affected frequency of identified organisms.

It is important to emphasise the differences in frequency of pathogens identified in Asian compared to European or North American studies. For example, in a study of hospitalized CAP patients, S. pneumoniae appeared to have a lower frequency (13\% v 26\%) and Enterobacteriacae appeared to have a higher frequency (9\% v 2.7\%) in in Asian studies as compared to European studies. ${ }^{5}$ Similarly, while limited comparison was possible in our study, the frequency of certain nosocomial pathogens appeared to be higher in Asia or AsiaPacific regions (Online only Table IV) in keeping with higher prevalence of hospitalacquired infection $(15.5 \%)$ in comparison to Europe (7.1\%) or the USA (4\%). ${ }^{31}$ However this incongruity may be as a result of selection pressure on clinically relevant bacteria from differing prior antibiotic exposure of patients across continents, as well as possible implementation of pneumococcal vaccination programmes. 
The scarce amount of available data on microbiological etiologies of pneumonia complicating stroke might also reflect the clinical routine, as suggested by a recent survey on German stroke units. ${ }^{32}$ Treatment guidelines for pneumonia complicating stroke, nevertheless, should take into account these commonly isolated organisms and also consider local surveillance data, community pathogens and demographical variations, together with guidance from the WHO global strategy for containment of antimicrobial resistance ${ }^{33}$ when recommendations are being made for prescribing empirical antibiotic regimens. Anaerobes, while not identified in our study, are commonly seen in the upper airway mixed with oral flora and in the stomach, are often thought to be responsible for aspiration pneumonia. However anaerobes are difficult to culture, and if aspiration is suspected, then broader spectrum antibiotics may be required. ${ }^{28}$

The risk of contamination with oral flora, low diagnostic yield (30-40\% sensitivity) with current diagnostic methods ${ }^{31}$ and delay in producing a positive result (at least $24 \mathrm{hrs}-48 \mathrm{hrs}$ ) often predisposes to initial broad spectrum antibiotic prescriptions. An ideal diagnostic method would be more timely and sensitive to identifying pathogens. PCR assays involving comprehensive molecular testing platforms significantly improve pathogen detection $(87 \% \mathrm{~V}$ $39 \%$ ) in comparison to sputum culture (including viral pathogens) and provide results within 24hrs, which may help in initiation of pathogen directed microbial therapy or a rapid deescalation of broad spectrum antibiotic therapy. ${ }^{29}$ However, validating such technology still depends on a reliable microbiological reference standard (sputum analysis) which may limit its potential utility in non-ventilated stroke patients. 


\section{Conclusion}

Our study demonstrates an evidence gap in appropriately designed studies that robustly identify microbiological etiologies in pneumonia complicating stroke. Although limited by small and heterogeneous study samples, this review suggests AGNB and GPC species are frequently associated with pneumonia complicating stroke. Difficulties in obtaining suitable sputum samples among non-ventilated stroke patients and poor sensitivity of current diagnostic methods often results in broad spectrum antibiotic prescriptions for pneumonia. Our study however supports the need for a consensus based approach to antibiotic initiation and further targeted antibiotic treatment trials for enhanced antibiotic stewardship.

Acknowledgements: We would like to acknowledge Dr Ryan Keh (Speciality Trainee in Neurology, Salford Royal NHS Foundation Trust) and Dr Luciana Miguel Alhambra (Clinical Fellow in Stroke Medicine, Salford Royal NHS Foundation Trust) for their assistance in translating Non-English language studies for this review.

Sources of Funding: None for the systematic review. Dr Meisel is supported by the German Research Foundation (EXC257 and SFB-TR84).

\section{Disclosures/Conflicts of Interest:}

Dr Meisel received project funding by Thermo Fisher Scientific BRAHMS GmbH, Germany for a stroke trial. 


\section{Figure legends}

Figure 1: Flow diagram of systematic search methodology

Figure 2: Forest plot of pneumonia frequency according to stroke subtype

Fig 3: Proportion of studies identifying the eight most commonly isolated organisms 


\section{References}

1. Kishore AK, Vail A, Chamorro A, Garau J, Hopkins SJ, Di Napoli M, et al. How is pneumonia diagnosed in clinical stroke research? A systematic review and meta-analysis. Stroke. 2015; 46:1202-1209.

2. Westendorp WF, Nederkoorn PJ, Vermeij JD, Dijkgraaf MG, van de Beek D. Post-stroke infection: a systematic review and meta-analysis. BMC Neurology.2011; 11:110.

3. Smith CJ, Kishore AK, Vail A, Chamorro A, Garau J, Hopkins SJ, et al. Diagnosis of stroke-associated pneumonia: recommendations from the Pneumonia In Stroke ConsEnsuS Group. Stroke. 2015; 46:2335-2340.

4. Harms H, Hoffmann S, Malzahn U, Ohlraun S, Heuschmann P, Meisel A. Decisionmaking in the diagnosis and treatment of stroke-associated pneumonia. $\mathbf{J}$ Neurol Neurosurg Psychiatry. 2012; 83:1225-30.

5. Peto L, Nadjm B, Horby P, Dieu Ngan TT, van Doorn Ra, Kinh NV, et al. The bacterial aetiology of adult community-acquired pneumonia in Asia: a systematic review. Trans $R$ Soc Trop Med Hyg. 2014; 108: 326-337.

6. Campbell SG, Marrie TJ, Anstey R, Dickinson G, Ackroyd-Stolarz S. The contribution of blood cultures to the clinical management of adult patients admitted to the hospital with community-acquired pneumonia: a prospective study. Chest.2003; 123:1142-50.

7. Adams HP, del Zoppo G, Alberts MJ, Bhatt DL, Brass L, Furlan A, et al. Guidelines for the early management of adults with ischemic stroke: a guideline from the American Heart Association/American Stroke Association Stroke Council, Clinical Cardiology Council, Cardiovascular Radiology and Intervention Council, and the Atherosclerotic Peripheral Vascular Disease and Quality of Care Outcomes in Research Interdisciplinary 
Working Groups: the American Academy of Neurology affirms the value of this guideline as an educational tool for neurologists. Stroke.2007; 38:1655-711.

8. Guidelines for management of ischaemic stroke and transient ischaemic attack.

Cerebrovasc Dis. 2008; 25:457-507.

9. Shamseer L, Moher D, Clarke M, Ghersi D, Liberati A, Petticrew M, et al, PRISMA-P

Group. Preferred reporting items for systematic review and meta-analysis protocols

(PRISMA-P): elaboration and explanation. BMJ. 2015; 349:g7647.

10. Higgins JPT, Green S (eds). Cochrane Handbook for Systematic Reviews of Interventions Version 5.0.2 [updated September 2009]. The Cochrane Collaboration, 2009. Available from www.cochrane-handbook.org (accessed $22^{\text {nd }}$ February 2017).

11. Chamorro A, Horcajada JP, Obach V, Vargas M, Revilla M, Torres F, et al. The Early Systemic Prophylaxis of Infection After Stroke study: a randomised clinical trial. Stroke 2005; 36: 1495-500.

12. Hassan A, Khealani BA, Shafqat S, Aslam M, Salahuddin N, Syed N A, et al. Strokeassociated pneumonia: microbiological data and outcome. Singapore Med J. 2006; 47: 204207.

13. Vargas M, Horcajada JP, Obach V, Revilla M, Cervera A, Torres F, et al. Clinical consequences of infection in patients with acute stroke: is it prime time for further antibiotic trials? Stroke. 2006; 37: 461-65.

14. Ros L, García M, Prat J, González C, Gimeno C Albert A, et al. Factores predisponentes a la infección nosocomial en el ictus agudo y su influencia en la morbimortalidad. Med Clin (Barc). 2007; 128:441-7.

15. Harms H, Prass K, Meisel C, Klehmet J, Rogge W, Drenckhahn C, et al. Preventive antibacterial therapy in acute ischemic stroke: a randomised controlled trial. PLoS One. 2008; 3: e2158. 
16. Sui R, Zhang L. Risk factors of stroke-associated pneumonia in Chinese patients. Neurological Research.2011; 33:508:514.

17. Yeh S, Huang K, Wang T, Chen Y, Chen C, Tang S, et al. Dysphagia screening decreases pneumonia in acute stroke patients admitted to the stroke intensive care unit. Journal of the Neurological Sciences. 2011; 306:38-41.

18. Fluri F, Morgenthaler NG, Mueller B, Christ-Crain M, Katan M. Copeptin, Procalcitonin and Routine Inflammatory Markers-Predictors of Infection after Stroke. PLoS ONE. 2012; 7: e48309.

19. Chen L, Chang C, Hsu L, Tsai P, Chang S, Chang S, et al. Bacterial pneumonia following acute ischemic stroke. Journal of the Chinese Medical Association. 2013; 76:78-82 20. Chen CM, Hsu HC, TsaiWS, Chang CH, Chen KH, Hong CZ. Infections in acute older stroke inpatients undergoing rehabilitation. Am J Phys Med Rehabil.2012; 91:211-219.

21. Satou Y, Oguro H, Murakami Y, Onoda K, Mitaki S, Hamada C, et al. Gastroesophageal Reflux during Enteral Feeding in Stroke Patients: A 24-hour Esophageal pH-monitoring Study. Journal of Stroke and Cerebrovascular Diseases. 2013; 22:185-189.

22. Becker KJ, Dankwa D, Lee R, Schulze J, Zierath D, Tanzi P, et al. Stroke, IL-1ra, IL1RN, Infection and Outcome. Neurocrit Care. 2014; 21:140-146.

23. Warusevitane A, Karunatilake D, Sim J Lally F, Roffe C. Safety and Effect of Metoclopramide to Prevent Pneumonia in Patients With Stroke Fed via Nasogastric Tubes Trial. Stroke. 2015; 46:454-460.

24. Li Y, Song B, Fang H, Gao Y, Zhao L, Xu Y. External validation of the A2DS2 score to predict stroke-associated pneumonia in a Chinese Population: a prospective cohort study. PLoS ONE. 2014; 9: e109665. 
25. Westendorp WF, Vermeij JD, Zock E, Hooijenga IJ, Kruyt ND, Bosboom HJ, et al for the PASS investigators. The Preventive Antibiotics in Stroke Study (PASS): a pragmatic randomised open-label masked endpoint clinical trial. Lancet.2015; 385: 1519-26. 26. Jones RN. Microbial Etiologies of Hospital-Acquired Bacterial Pneumonia and Ventilator-Associated Bacterial Pneumonia. Clinical Infectious Diseases. 2010; 51:S81-S87. 27. Garau J, Calbo E. Community acquired pneumonia. Lancet.2008; 371:455-458 28. Armstrong JR, Mosher BD. Aspiration Pneumonia After Stroke. Neurohospitalist. 2011;1:85-93.

29. Gadsby NJ, Russell CD, McHugh MP, Mark H, Morris AC, Laurenson IF, et al. Comprehensive Molecular Testing for Respiratory Pathogens in Community-Acquired Pneumonia. Clinical Infectious Diseases.2016; 62:817-23.

30. Jain S, Self WH, Wunderink RG, Fakhran S, Balk R, Bramley AM, et al. CommunityAcquired Pneumonia Requiring Hospitalization among U.S. Adults. $N$ Engl J Med. 2015;373:415-27.

31. Allegranzi B, Nejad SB, Combescure C, Graafmans W, Attar H, Donaldson L. Burden of endemic health-care-associated infection in developing countries: systematic review and meta-analysis. Lancet. 2011; 377:228-41.

32. Harms H, Hoffmann S, Malzahn U, Ohlraun S, Heuschmann P, Meisel A, et al. Decisionmaking in the diagnosis and treatment of stroke-associated pneumonia. J Neurol Neurosurg Psychiatry.2012; 83: 1225-1230.

33. WHO (World Health Organization). 2015. Global Action Plan on Antimicrobial Resistance. Available on: http://www.who.int/antimicrobial-resistance/publications/globalaction-plan/en/ [accessed 10 November 2017]. 
Table 1: Study characteristics

\begin{tabular}{|c|c|c|c|c|c|c|c|c|c|c|c|c|c|c|c|}
\hline First Author & $\begin{array}{c}\text { Year of } \\
\text { recruitment }\end{array}$ & Year Published & Country & Design & Participants (n) & Stroke Type & Setting & $\begin{array}{c}\text { Mean } \\
\text { Age (y) }\end{array}$ & $\begin{array}{l}\text { Male } \\
(\%)\end{array}$ & $\begin{array}{c}\text { Mean } \\
\text { NIHSS }\end{array}$ & $\begin{array}{c}\text { Time to } \\
\text { pneumonia } \\
\text { diagnosis (d) }\end{array}$ & Culture specimen & $\begin{array}{c}\text { Positive culture } \\
(\%)\end{array}$ & 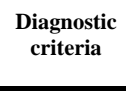 & $\begin{array}{c}\text { Pneumonia } \\
\text { risk } \\
\text { stratification }\end{array}$ \\
\hline Chamorro & 2002-2004 & 2005 & Spain & 1 & 136 & 2 & 1 & 72.9 & 50 & 12 & $66 \%<7 \mathrm{~d}$ & $\begin{array}{l}\text { sputum/tracheal } \\
\text { aspirate }\end{array}$ & 45 & 2 & 2 \\
\hline Hassan & 1998-2001 & 2006 & Pakistan & 3 & 443 & 2 & 1 & 64 & 68 & NR & $67 \%<2 \mathrm{~d}$ & $\begin{array}{l}\text { sputum/tracheal } \\
\text { aspirate }\end{array}$ & 38 & 1 & 2 \\
\hline Vargas & $2001-2002$ & 2006 & Spain & 2 & 229 & 2 & 1 & 72.3 & 51 & 9 & $\leq 7 \mathrm{~d}$ & tracheal aspirate & 41 & 2 & 2 \\
\hline Ros & 1998-1999 & 2007 & Spain & 2 & 258 & 2 & 1 & 74.9 & 48.8 & NR & NR & blood & 22 & 2 & 1 \\
\hline Harms & 2003-2006 & 2008 & Germany & 1 & 79 & 1 & 1 & 72.5 & NR & 16 & $\leq 11 \mathrm{~d}$ & tracheal aspirate & 45 & 1 & 3 \\
\hline Sui & 2000-2009 & 2011 & China & 3 & 1435 & 2 & 2 & 67.2 & 55.4 & 7 & $63 \%<3 d$ & sputum & 38 & 1 & 2 \\
\hline Yeh & 2006-2007 & 2011 & Taiwan & 3 & 163 & 2 & 2 & 67.4 & 54 & 14 & NR & sputum & 39 & 1 & 3 \\
\hline Fluri & 2006-2007 & 2012 & Switzerland & 2 & 383 & 1 & 1 & 71.4 & 57.7 & 5 & $\leq 5 \mathrm{~d}$ & sputum/blood & 15 & 1 & 1 \\
\hline Chen & $2002-2010$ & 2012 & Taiwan & 3 & 341 & 2 & 3 & 73.4 & 48.6 & NR & $\mathrm{NR}$ & sputum & NR & 3 & 2 \\
\hline Chen & 2006-2011 & 2013 & Taiwan & 3 & 495 & 1 & 4 & 80.3 & 72.5 & 15 & $53 \%<3 d$ & sputum/blood & 75 & 1 & 2 \\
\hline Satou & NR & 2013 & Japan & 2 & 16 & 1 & 1 & 83.2 & NR & NR & NR & NR & 30 & 2 & $3^{*}$ \\
\hline Becker & 2005-2009 & 2014 & USA & 2 & 113 & 1 & 1 & 58 & 66 & 10 & $<15 \mathrm{~d}$ & sputum & 88 & 2 & 1 \\
\hline Warusevitane & 2008-2011 & 2014 & UK & 1 & 60 & 2 & 1 & 77.5 & 37 & 19 & $94 \%<7 d$ & sputum & 41 & 4 & $3 *$ \\
\hline $\mathrm{Li}$ & 2009-2011 & 2014 & China & 3 & 1279 & 1 & 1 & 63 & NR & $\mathrm{NR}$ & $\mathrm{NR}$ & sputum & $\mathrm{NR}$ & 2 & 1 \\
\hline Westendorp & 2010-2014 & 2015 & Netherlands & 1 & 2538 & 2 & 1 & 73.5 & 57 & 5 & NR & sputum/blood & 17 & 1 & 1 \\
\hline
\end{tabular}

Design-1 = randomized controlled study, 2 = prospective observational study, 3 = retrospective study; Stroke type- $1=$ ischemic stroke, $2=$ ischemic stroke and intracerebral hemorrhage; Setting-

$1=$ Acute Stroke Unit (ASU); 2=Stroke Intensive Care; $3=A S U$ and rehabilitation unit; $4=U n c l e a r ; C$ Criteria-1=Centers for Disease Control and Prevention Criteria, $2=$ Ad hoc Objective

criteria, $3=$ Mann Criteria, 4=British Thoracic Society Criteria $;$ NIHSS=National Institutes of Health Stroke Scale; NR=not reported; Pneumonia risk stratification criteria-1=low risk

(unselected stroke patients with $\leq 15 \%$ intracerebral haemorrhage, mean NIHSS $\leq 5) 2=$ high risk $(\geq 15 \%$ intracerebral haemorrhage,NIHSS $\geq 5$ ), $3=v e r y$ high risk ( exclusively dysphagia studies

and/or tube-fed patients* ; studies involving stroke patients in intensive care) 
Table 2: Frequency of isolated organisms in pneumonia complicating stroke in comparison to other forms of pneumonia

\begin{tabular}{|c|c|c|c|c|}
\hline Identified organisms & HAP (range, $\%)^{26}$ & $\mathrm{VAP}(\text { range, } \%)^{26}$ & CAP (range, $\%$ ) & $\begin{array}{l}\text { Pneumonia complicating stroke } \\
\text { (Weighted average with range, \%) }\end{array}$ \\
\hline \multicolumn{5}{|l|}{ Gram Positive Cocci } \\
\hline Staphylococcus aureus & $26.6-36.5$ & $19.5-31.9$ & $3-14.1$ & $10.1(0-36.3)$ \\
\hline Streptococcal pneumoniae & $1.8-3.2$ & $<3$ & $35-80$ & $3.5(0-10.7)$ \\
\hline \multicolumn{5}{|l|}{ Gram Negative Bacilli } \\
\hline Klebsiella pneumoniae & $8-10.5$ & $6.6-10.2$ & $3-6$ & $12.8(0-51)$ \\
\hline Escherichia coli & 4.6-10.1 & $3-5$ & $6-12$ & $9(0-21.7)$ \\
\hline Pseudomonas aeruginosa & $19-22.4$ & $21.4-26.6$ & $2.8-9$ & $6(0-11.7)$ \\
\hline Acinetobacter baumanii & $4.4-13.3$ & 14.3 & $3-14.3$ & $4.6(0-22.9)$ \\
\hline Haemophilus influenzae & $1.3-3.7$ & NR & $5-40$ & $1.9(0-11.5)$ \\
\hline Enterobacter cloacae & $6.3-8.5$ & $6-8.8$ & NR & $1.7(0-10)$ \\
\hline
\end{tabular}


Fig. 1

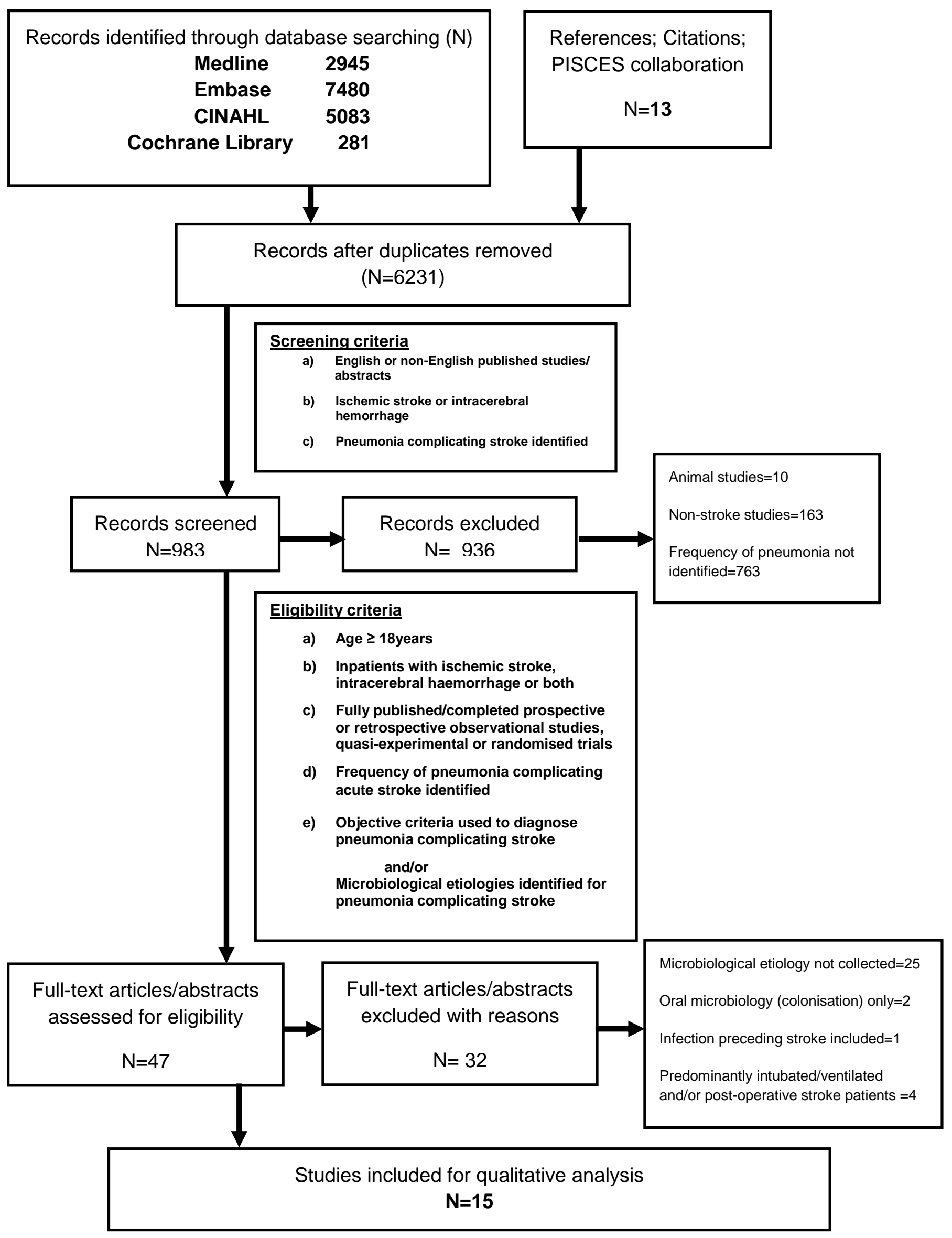


Fig. 2

$\begin{array}{lll}\text { Author } & \text { Participant (n) } & \text { Proportion (\%) } \\ \text { Satou } & 16 & 63 \\ \text { Harms } & 79 & 14 \\ \text { Becker } & 113 & 8 \\ \text { Fluri } & 383 & 5 \\ \text { Chen } & 495 & 10 \\ \text { Li } & 1279 & 24 \\ \text { Pooled (Ischemic) } & 16 \\ \text { Warusevitane } & 60 & 57 \\ \text { Chamorro } & 136 & 20 \\ \text { Yeh } & 163 & 51 \\ \text { Vargas } & 229 & 18 \\ \text { Ros } & 258 & 23 \\ \text { Chen } & 341 & 30 \\ \text { Hassan } & 443 & 23 \\ \text { Sui } & 1435 & 38 \\ \text { Westendorp } & 2538 & 2 \\ \text { Pooled (Mixed } & \text { stroke) } & 27 \\ \text { Total (I'=99\%) } & & 23\end{array}$

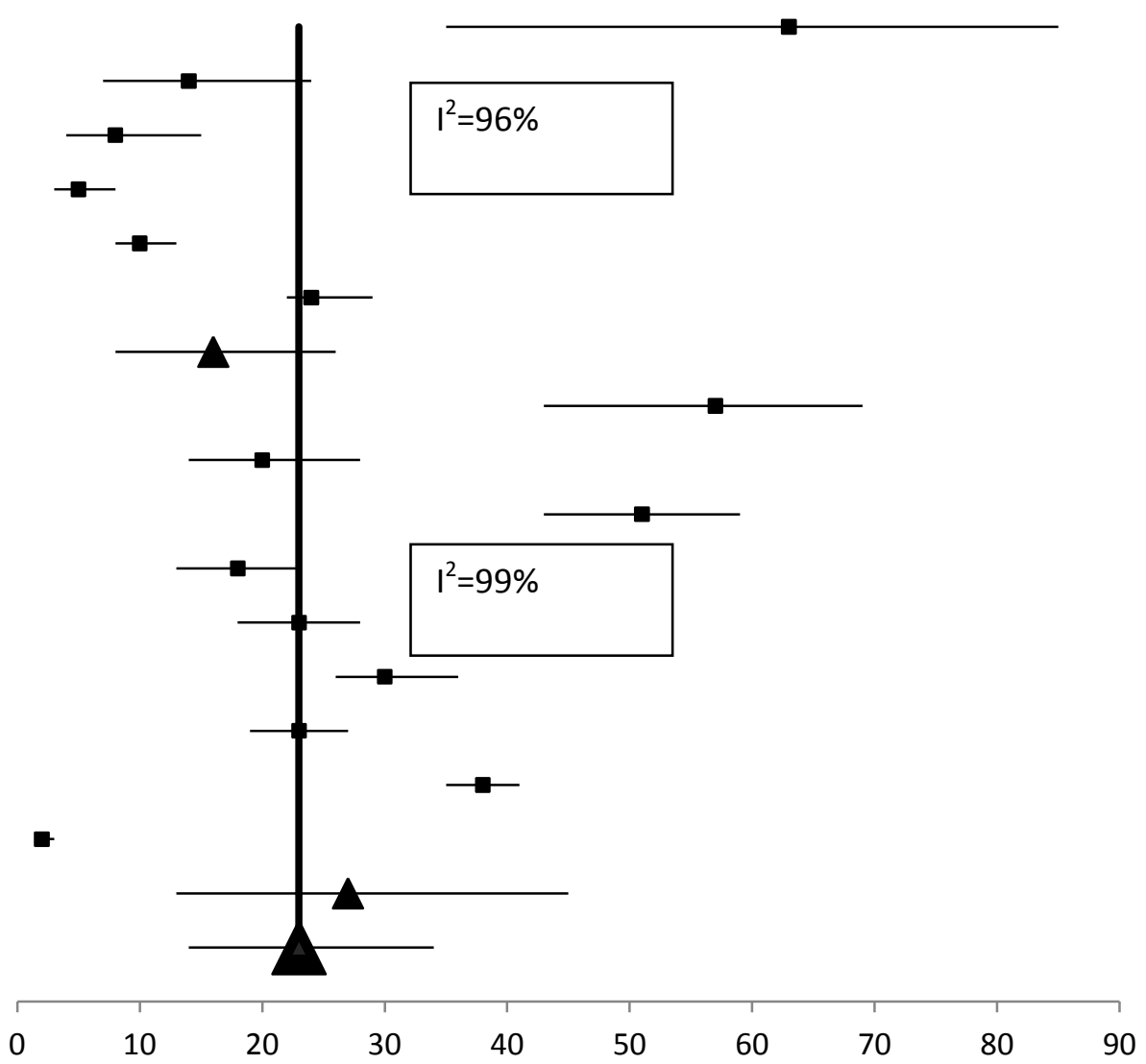




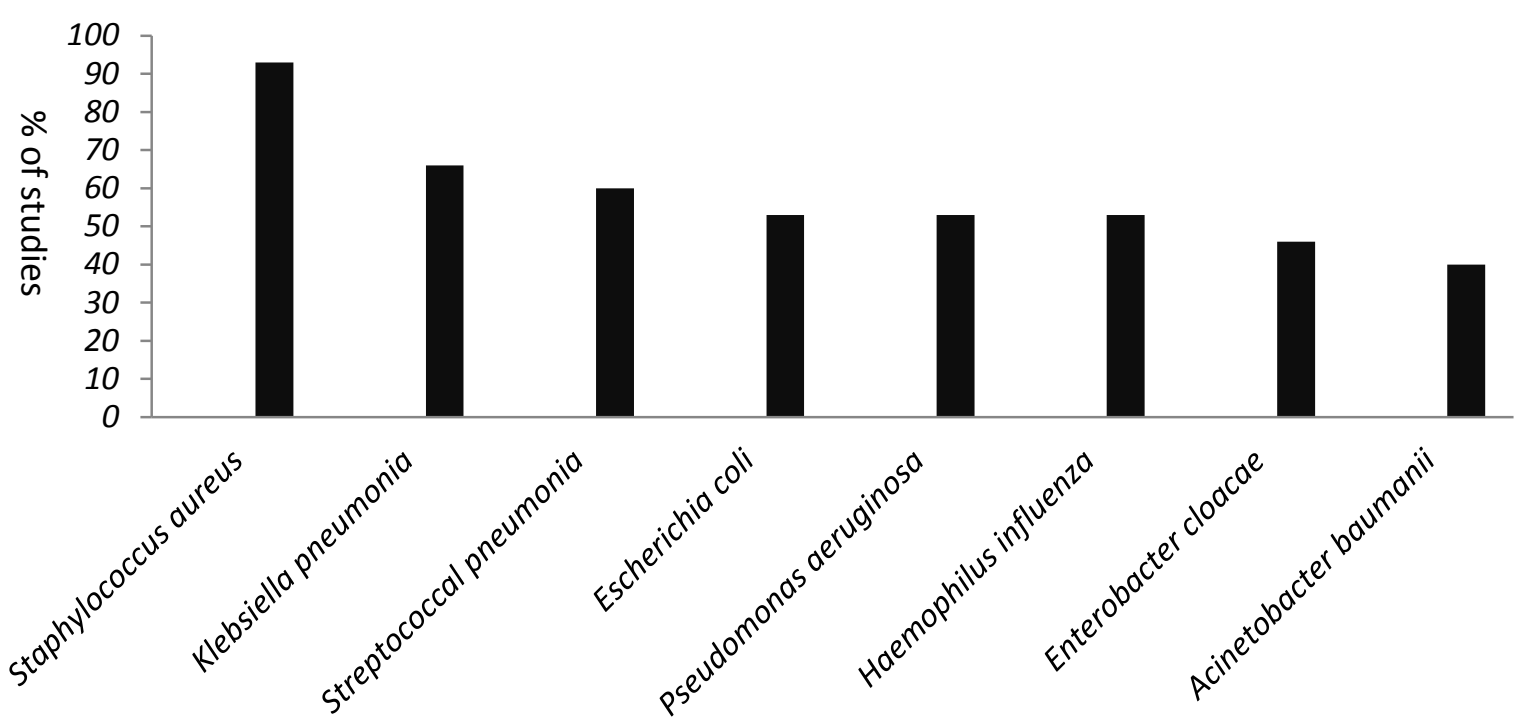

Fig. 3 


\section{SUPPLEMENTAL MATERIAL}

\section{Microbiological etiologies of pneumonia complicating stroke: A systematic review}

Amit K Kishore ${ }^{1,2}$ FRCP, Andy Vail ${ }^{3}$ MSc, Adam Jeans ${ }^{4} \mathrm{MD}$, Angel Chamorro ${ }^{5} \mathrm{PhD}$, Mario Di Napoli ${ }^{6} \mathrm{MD}$, Lalit Kalra ${ }^{7} \mathrm{PhD}$, Peter Langhorne ${ }^{8} \mathrm{PhD}$, Christine Roffe ${ }^{9} \mathrm{MD}$, Willeke Westendorp ${ }^{10}$ MD, Paul J Nederkoorn ${ }^{10} \mathrm{PhD}$, Javier Garau ${ }^{11}$, PhD, Diederik van de Beek ${ }^{10}$ $\mathrm{PhD}$, Joan Montaner ${ }^{12,13} \mathrm{PhD}$, Mark Woodhead ${ }^{14} \mathrm{DM}$, Andreas Meise ${ }^{15} \mathrm{MD}$, Craig J Smith ${ }^{1} \mathrm{MD}$, on behalf of Pneumonia In Stroke ConsEnsuS (PISCES) Group.

${ }^{1}$ Greater Manchester Comprehensive Stroke Centre, Manchester Academic Health Science Centre, Salford Royal Foundation Trust, UK; ${ }^{2}$ Division of Cardiovascular Sciences, University of Manchester, Manchester, UK; ${ }^{3}$ Centre for Biostatistics, University of Manchester, Salford Royal Foundation Trust, UK; ${ }^{4}$ Department of Microbiology, Salford Royal NHS Foundation Trust; ${ }^{5}$ Comprehensive Stroke Center, Department of Neuroscience, Hospital Clinic, University of Barcelona, Barcelona, Spain; ${ }^{6}$ Neurological Service, San Camillo de' Lellis General Hospital, Rieti, Italy; ${ }^{7}$ Clinical Neurosciences, King's College Hospital NHS Foundation Trust London, UK; ${ }^{8}$ Institute of Cardiovascular and Medical Sciences, University of Glasgow, Glasgow Royal Infirmary, Glasgow, UK; ${ }^{9}$ Keele University Institute for Science and Technology in Medicine, Guy Hilton Research Centre, Stoke-onTrent, UK; ${ }^{10}$ Department of Neurology, Center for Infection and Immunity Amsterdam (CINIMA), Academic Medical Center, University of Amsterdam, Amsterdam, Netherlands; ${ }^{11}$ Department of Medicine, Hospital Universitari Mutua de Terrassa, Barcelona, Spain;

${ }^{12}$ Neurovascular Research Lab, Vall d'Hebron Research Institute, Barcelona, Spain; ${ }^{13}$ Institute de Biomedicine of Seville, IBiS/Hospital Universitario Virgen del Rocío, University of Seville, Seville, Spain; ${ }^{14}$ Faculty of Medical and Human Sciences, University of Manchester \& Department of Respiratory Medicine, Central Manchester University Hospitals NHS Foundation Trust, Manchester Academic Health Science Centre, Manchester, UK; ${ }^{15}$ NeuroCure Clinical Research Center, Center for Stroke Research Berlin Department of Neurology Charité Universitaetsmedizin Berlin, Germany

Cover title: Bacterial etiology of pneumonia complicating stroke

Corresponding author: Dr Amit K Kishore

Greater Manchester Neurosciences Centre, Salford Royal NHS Foundation Trust, Stott lane, Salford, M6 8HD, UK; 
Online only Table I: Search Terms

\begin{tabular}{|c|c|c|}
\hline Search Areas & Thesaurus terms & Free Text Terms \\
\hline \multirow[t]{2}{*}{ MEDLINE } & $\begin{array}{l}\text { Subject Search in MESH: exp } \\
\text { *Cerebrovascular disorders/; exp } \\
\text { *Pneumonia/; }\end{array}$ & $\begin{array}{l}\text { Stroke*,Pneumonia*, "respiratory } \\
\text { tract infection*", "chest infection*", }\end{array}$ \\
\hline & [Limit to: Publication Year 1946-2016] & $\begin{array}{l}\text { [Limit to: Publication Year 1946- } \\
\text { 2016] }\end{array}$ \\
\hline EMBASE & $\begin{array}{l}\text { Subject Search on EMTREE: exp } \\
\text { *Cerebrovascular disease/ exp } \\
\text { *Pneumonia/; } \\
\text { [Limit to: Publication Year 1901-2016] }\end{array}$ & $\begin{array}{l}\text { Stroke*, Pneumonia*, "respiratory } \\
\text { tract infection*", "chest infection*" } \\
\text { [Limit to: Publication Year 1901- } \\
\text { 2016] }\end{array}$ \\
\hline \multirow[t]{2}{*}{ CINAHL } & $\begin{array}{l}\text { Subject Search: exp *Cerebrovascular } \\
\text { disorders/; exp *Pneumonia/; }\end{array}$ & $\begin{array}{l}\text { Stroke*,Pneumonia*, "respiratory } \\
\text { tract infection*", "chest infection*" }\end{array}$ \\
\hline & [Limit to: Publication Year 1946-2016] & $\begin{array}{l}\text { [Limit to: Publication Year } 1901 \text { to } \\
\text { 2016] }\end{array}$ \\
\hline \multirow[t]{2}{*}{$\begin{array}{l}\text { Cochrane Cochrane Central } \\
\text { Register of Controlled Trials }\end{array}$} & [Limit to: Publication Year 1980-2016] & All text: "stroke" "pneumonia" \\
\hline & & $\begin{array}{l}\text { Publication Year from } 1980 \text { to } 2016 \text {, } \\
\text { in Cochrane Reviews (Protocols only), } \\
\text { Trials and Methods Studies (Word } \\
\text { variations have been searched) }\end{array}$ \\
\hline
\end{tabular}


Online only Table II: Eligibility criteria

\section{Inclusion criteria:}

Age $\geq 18$ years

Fully published studies or abstracts

English or non-English language

Inpatients with ischemic stroke, intracerebral haemorrhage, or both

Randomized (RCT's) and other controlled trials, including cluster RCTs, controlled (nonrandomized) clinical trials (CCTs) or cluster trials, prospective comparative cohort studies, retrospective observational studies, case-control or nested case-control studies.

Incidence or prevalence of pneumonia following admission with stroke reported

Possible microbiological etiologies identified as responsible for pneumonia complicating stroke OR objective criteria used for diagnosing pneumonia

\section{Exclusion criteria:}

Age $<18$ years

Exclusively intubated and mechanically ventilated patients

Exclusively pneumonia preceding index stroke

Case reports 
Online only Table III: Patient characteristics

\begin{tabular}{|c|c|c|c|c|c|c|c|c|c|c|c|}
\hline \multirow[t]{2}{*}{ Author } & \multirow{2}{*}{$\begin{array}{l}\text { NG or PEG } \\
\text { feeding }(\%)\end{array}$} & \multirow{2}{*}{$\begin{array}{l}\text { Prophylactic } \\
\text { antibiotics }\end{array}$} & \multicolumn{8}{|c|}{ Co-morbidities (\%) } & \multirow[t]{2}{*}{ MV (\%) } \\
\hline & & & COPD/other lung pathology & Immunosuppression & $\begin{array}{l}\text { Previous } \\
\text { Stroke }\end{array}$ & Smoking history & Heart disease & $\mathbf{A F}$ & HTN & DM & \\
\hline Chamorro $^{1}$ & 48 & Yes & 9.5 & Excluded & 17.6 & 16.9 & 12.5 & NR & 63.2 & 22.8 & 0 \\
\hline Hassan $^{2}$ & $\mathrm{NR}$ & No & $\mathrm{NR}$ & NR & NR & NR & NR & NR & NR & NR & 0 \\
\hline Vargas $^{3}$ & 42 & NR & 10 & 4.3 & 16.1 & 16 & NR & NR & 60 & 19 & 0 \\
\hline $\operatorname{Ros}^{4}$ & NR & NR & NR & NR & 12.4 & NR & 13.2 & 12.8 & 63.2 & 35.3 & 0 \\
\hline Harms $^{5}$ & 66 & Yes & 7.5 & 8.8 & 11.4 & 11.4 & 37.2 & 34.1 & 64.5 & 31.6 & 8.8 \\
\hline $\mathrm{Sui}^{6}$ & 47 & NR & NR & NR & NR & 49 & 32 & NR & NR & 44 & 2.2 \\
\hline Yeh $^{7}$ & 73 & No & NR & NR & NR & NR & NR & NR & NR & NR & 12.2 \\
\hline Fluri $^{8}$ & $\mathrm{NR}$ & NR & $\mathrm{NR}$ & $\mathrm{NR}$ & NR & NR & 34 & 19.4 & 80 & 19.3 & 0 \\
\hline Chen ${ }^{9}$ & 58 & NR & NR & NR & NR & NR & NR & NR & 82 & 39 & 0.3 \\
\hline Chen $^{10}$ & NR & NR & $25.5^{*}$ & $14^{*}$ & $31.4^{*}$ & $43 *$ & $27.5^{*}$ & NR & $\begin{array}{l}70.6 \\
*\end{array}$ & $29.4 *$ & $23.5^{*}$ \\
\hline Satou $^{11}$ & 100 & NR & NR & NR & NR & NR & NR & NR & NR & NR & NR \\
\hline Becker $^{12}$ & $\mathrm{NR}$ & No & NR & Excluded & 35.3 & 37 & 24 & NR & 53.1 & 24 & NR \\
\hline Warusevitane $e^{13}$ & 100 & No & 16 & NR & NR & NR & NR & 60 & 66 & 28 & 0 \\
\hline $\mathbf{L i}^{14}$ & NR & NR & NR & NR & NR & 40 & NR & NR & 74 & 20 & NR \\
\hline Westendorp ${ }^{15}$ & NR & Yes & 8.2 & 17.3 & 32.5 & 24.4 & 13 & 15.4 & 55.2 & 19.7 & 0 \\
\hline
\end{tabular}

NR=Not Reported, $C O P D=$ Chronic Obstructive Pulmonary Disease, AF=Atrial fibrillation, $H T N=$ hypertension, DM=diabetes mellitus, MV=mechanical ventilation, * with pneumonia 
Online only Table IV: The eight most commonly isolated organisms in positive cultures (\%) in the included studies

\begin{tabular}{|c|c|c|c|c|c|c|c|c|c|c|c|c|c|c|c|}
\hline & \multicolumn{8}{|c|}{ European or North American Studies } & \multicolumn{7}{|c|}{ Asian Studies } \\
\hline & Chamorro & Vargas & Ros & Harms & Fluri & Becker & Warusevitane & Westendorp & Sui & Yeh & $\mathbf{L i}$ & Satou & Hassan & Chen & Chen \\
\hline \multicolumn{16}{|l|}{ GRAM POSITIVE COCCI } \\
\hline Staphylococcus aureus & 11 & $x$ & 5 & 36.3 & 5 & 22.2 & 11.7 & 1.7 & 9.3 & 19.2 & 6.8 & 20 & 11.7 & 24.1 & 1.9 \\
\hline Streptococcal pneumoniae & 3.7 & 2.4 & $x$ & 9 & $x$ & $x$ & $x$ & 1.7 & 0.5 & 1.2 & 10.7 & $x$ & 3.9 & 2.8 & 1 \\
\hline \multicolumn{16}{|l|}{ GRAM NEGATIVE BACILLI } \\
\hline Klebsiella pneumoniae & $x$ & $x$ & 5 & $x$ & $x$ & 11.1 & 11.7 & $x$ & 8.8 & 51 & 18.2 & 10 & 3.9 & 15.4 & 23.5 \\
\hline Escherichia coli & $x$ & 7.3 & $x$ & $x$ & $x$ & $x$ & 5.8 & $x$ & 7.7 & 9 & 21.7 & $x$ & 1.9 & 2.8 & 10 \\
\hline Enterobacter cloacae & $x$ & 7.3 & 1.7 & $x$ & $x$ & $x$ & 5.8 & $x$ & $x$ & 9.6 & $x$ & $x$ & 1.9 & 3.8 & 10 \\
\hline Pseudomonas aeruginosa & $x$ & 2.4 & $x$ & $x$ & $x$ & 11.1 & $x$ & $x$ & 6.6 & 4.8 & 8.2 & $x$ & 11.7 & 6.7 & 3.9 \\
\hline Haemophilus influenzae & 3.7 & 21.9 & $x$ & $x$ & 5 & 11.1 & $x$ & $x$ & 6.6 & $x$ & $x$ & $x$ & 3.9 & 11.5 & 7.8 \\
\hline Acinetobacter baumanii & $x$ & $x$ & $x$ & $x$ & $x$ & $x$ & $x$ & $x$ & 1.4 & 22.9 & 8.4 & $x$ & 3.9 & 6.7 & 7.8 \\
\hline
\end{tabular}


Online only Table V: Definition of pneumonia terminologies

Types of pneumonia Definition

Hospitalized community acquired pneumonia

$(\mathrm{CAP})^{16}$

Hospital acquired pneumonia (HAP) ${ }^{17}$

Ventilator-associated pneumonia (VAP) ${ }^{17}$

Stroke associated pneumonia (SAP) ${ }^{18}$
Pneumonia i.e. symptoms and signs consistent with

an acute lower respiratory tract infection in the

community, associated with new radiographic

shadowing for which there is no other explanation

and needing hospital admission

Pneumonia in a hospitalised patient $>48-72$ hours

after admission, without any incubation period

Pneumonia in a patient occurring $>48-72$ hours

after intubation

Pneumonia in a patient $\leq 7$ days from stroke symptom

onset (HAP after this period); Early $\mathrm{SAP}<72 \mathrm{hrs}$, late

$\mathrm{SAP}>72 \mathrm{hrs}$ 


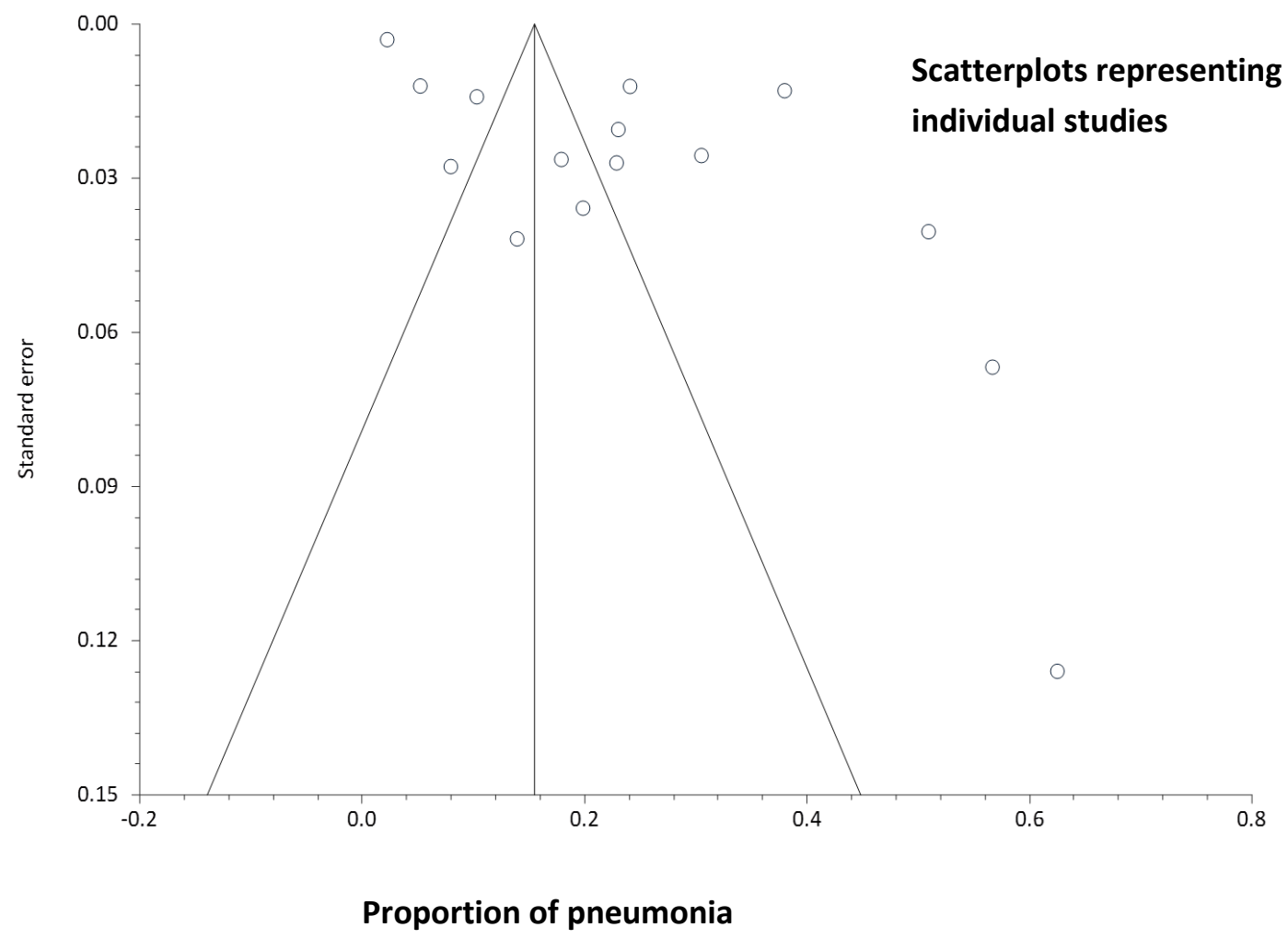

Online only Figure I: Funnel Plot 


\section{References}

1. Chamorro A, Horcajada JP, Obach V, Vargas M, Revilla M, Torres F, et al. The Early Systemic Prophylaxis of Infection After Stroke study: a randomised clinical trial. Stroke 2005; 36: 1495-500.

2. Hassan A, Khealani BA, Shafqat S, Aslam M, Salahuddin N, Syed N A, et al. Strokeassociated pneumonia: microbiological data and outcome. Singapore Med J. 2006; 47: 204207.

3. Vargas M, Horcajada JP, Obach V, Revilla M, Cervera A, Torres F, et al. Clinical consequences of infection in patients with acute stroke: is it prime time for further antibiotic trials? Stroke. 2006; 37: 461-65.

4. Ros L, García M, Prat J, González C, Gimeno C Albert A, et al. Factores predisponentes a la infección nosocomial en el ictus agudo y su influencia en la morbimortalidad. Med Clin (Barc). 2007; 128:441-7.

5. Harms H, Prass K, Meisel C, Klehmet J, Rogge W, Drenckhahn $C$, et al. Preventive antibacterial therapy in acute ischemic stroke: a randomised controlled trial. PLoS One. 2008; 3: e2158.

6. Sui R, Zhang L. Risk factors of stroke-associated pneumonia in Chinese patients. Neurological Research.2011; 33:508:514.

7. Yeh S, Huang K, Wang T, Chen Y, Chen C, Tang S, et al. Dysphagia screening decreases pneumonia in acute stroke patients admitted to the stroke intensive care unit. Journal of the Neurological Sciences. 2011; 306:38-41.

8. Fluri F, Morgenthaler NG, Mueller B, Christ-Crain M, Katan M. Copeptin, Procalcitonin and Routine Inflammatory Markers-Predictors of Infection after Stroke. PLoS ONE. 2012; 7: e48309.

9. Chen L, Chang C, Hsu L, Tsai P, Chang S, Chang S, et al. Bacterial pneumonia following acute ischemic stroke. Journal of the Chinese Medical Association. 2013; 76:78-82

10. Chen CM, Hsu HC, TsaiWS, Chang CH, Chen KH, Hong CZ. Infections in

acute older stroke inpatients undergoing rehabilitation. Am J Phys Med Rehabil.2012;

91:211-219.

11. Satou Y, Oguro H, Murakami Y, Onoda K, Mitaki S, Hamada C, et al. Gastroesophageal

Reflux during Enteral Feeding in Stroke Patients: A 24-hour Esophageal pH-monitoring

Study. Journal of Stroke and Cerebrovascular Diseases. 2013; 22:185-189.

12. Becker KJ, Dankwa D, Lee R, Schulze J, Zierath D, Tanzi P, et al. Stroke, IL-1ra,

IL1RN, Infection and Outcome. Neurocrit Care. 2014; 21:140-146.

13. Warusevitane A, Karunatilake D, Sim J Lally F, Roffe C. Safety and Effect of

Metoclopramide to Prevent Pneumonia in Patients With Stroke Fed via Nasogastric Tubes Trial. Stroke. 2015; 46:454-460.

14. Li Y, Song B, Fang H, Gao Y, Zhao L, Xu Y.External validation of the A2DS2 score to predict stroke-associated pneumonia in a Chinese Population: a prospective cohort study. PLoS ONE. 2014; 9: e109665.

15. Westendorp WF, Vermeij JD, Zock E, Hooijenga IJ, Kruyt ND, Bosboom HJ, et al for the PASS investigators. The Preventive Antibiotics in Stroke Study (PASS): a pragmatic randomised open-label masked endpoint clinical trial. Lancet.2015; 385: 1519-26.

16. Guidelines for the management of community acquired pneumonia in adults: A quick reference guide (2009 update). British Thoracic Society Reports. 2009; 1

17. Armstrong JR, Mosher BD. Aspiration Pneumonia After Stroke. Neurohospitalist. 2011; 1: 85-93. 
18. Kishore AK, Vail A, Chamorro A, Garau J, Hopkins SJ, Di Napoli M, et al. How is pneumonia diagnosed in clinical stroke research? A systematic review and meta-analysis. Stroke. 2015; 46:1202-1209.

\section{$\underline{\text { References for excluded studies with reasons (32 studies) }}$}

\section{Infection preceding stroke included}

1. Grau AJ, Bugglea F, Schnitzlerb P, Spiela M, Lichya C, Hacke W. Fever and infection early after ischemic stroke. Journal of the Neurological Sciences. 1999; $115-120$.

\section{Oral microbiology (colonisation only)}

1. Gosney M, Martin MV, Wright AE. The role of selective decontamination of the digestive tract in acute stroke. Age and Ageing .2006; 35: 42-47.

2. Millns B ,Gosney M, Jack CIA, Martin MV, Wright AE . Acute Stroke Predisposes to Ora GramNegative Bacilli - a Cause of Aspiration Pneumonia. Gerontology 2003;49:173-176.

\section{Predominantly intubated/ventilated and/or post-operative stroke patients}

1. Gumbinger C, Hug A, Mürle B, Berger B, Zorn M, Becker K, et al. Early blood-based microbiological testing is ineffective in severe stroke patients. Journal of the Neurological Sciences. 2013; 325: 46-50.

2. Alsumrain M, Melillo N, Debari VA, Kirmani J, Moussavi M, Doraiswamy V, et al. Predictors and outcomes of pneumonia in patients with spontaneous intracerebral haemorrhage. Journal of Intensive Care Medicine.2013; 28:118-123.

3. Naidech AM, Liebling SM, Duran IM, Moore MJ, Wunderink RG, Zembower TR. Reliability of the validated clinical diagnosis of pneumonia on validated outcomes after intracranial hemorrhage. Journal of Critical Care.2012; 27:527.e7-11.

4. Divani AA, Hevesi M, Pulivarthi S, Luo X, Souslian F, Suarez JI, et al. Predictors of Nosocomial Pneumonia in Intracerebral Hemorrhage Patients: A Multi-center Observational Study. Neurocrit Care. 2015; 22:234-242.

\section{Microbiological etiology not collected}

1. WarneckeT, Ritter MA, Kröger B, Oelenberg, Teismann I, Heuschmann PU, et al. Fiberoptic endoscopic dysphagia severity scale predicts outcome after acute stroke. Cerebrovascular Diseases. 2009; 28:283-289.

2. Zhang X, Wang F, Zhang G, Ge Z. Risk Factors for Developing Pneumonia in Patients with Diabetes Mellitus Following Acute Ischaemic Stroke. The Journal of International Medical Research.2012; 40: 1860-1865.

3. Steinhagen, Grossman A, Benecke R, Walter U. Swallowing disturbance pattern relates to brain lesion location in acute stroke patients. Stroke.2009; 40:1903-1906.

4. Miles A, Zengc ISL, McLauchland H, Huckabeee M. Cough reflex testing in dysphagia following Stroke: A randomized controlled trial. Journal of Clinical Medicine Research. 2013;5:222-233.

5. Ji R, Shen H, Pan Y, Wang P, Liu G, Wang Y, et al: China National Stroke Registry Investigators. Novel risk score to predict pneumonia after acute ischemic stroke. Stroke.2013; 44:1303-1309. 
6. Minnerup J, Wersching H, Brokinkel B, Dziewas R, Heuschmann PU, Nabavi DG, et al. The impact of lesion location and lesion size on post stroke infection frequency. Journal of Neurology, Neurosurgery and Psychiatry. 2010; 81:198-202.

7. Vermeij FH, Reimer WJMS, Man P, Oostenbrugge RJV, Franke CL, Jong GD, et al. Stroke-associated infection is an independent risk factor for poor outcome after acute ischemic stroke: data from the Netherlands stroke survey. Cerebrovascular Diseases. 2009; 27:465-471.

8. Busti C, Agnelli G, Duranti M, Orlandi C, Marcucci M, Paciaroni M. Lung ultrasound in the diagnosis of stroke-associated pneumonia. Internal and EmergencyMedicine.2014; 9:173178.

9. Popovic N, Stefanovic-Budimkic M, Mitrovic N, Urosevic A, Milosevic B, Pelemis M, et al. The frequency of poststroke infections and their impact on early stroke outcome. Journal of Stroke and Cerebrovascular Diseases. 2013; 22:424-9.

10. Chumbler NR, Williams LS, Wells CK, Lo AC, Nadeau S, Peixoto AJ, et al. Derivation and validation of a clinical system for predicting pneumonia in acute stroke.

Neuroepidemiology.2010; 34:193-199.

11. Suntrup S, Warnecke T, Kemmling A, Teismann IK, Hamacher C, Oelenberg S.

Dysphagia in patients with acute striatocapsular haemorrhage. Journal of Neurology.2012; 259:93-99.

12. Titsworth WL, Abram J, Fullerton A, Hester J, Guin P, Waters MF, et al. Prospective quality initiative to maximize dysphagia screening reduces hospital-acquired pneumonia prevalence in patients with stroke. Stroke.2013; 44:3154-3160.

13. Arnold M, Liesirova K, Broeg-Morvay A, Meisterernst J, Schlager M, Mono M et al. Dysphagia in Acute Stroke: Incidence, Burden and Impact on Clinical Outcome. PLoS ONE . 2015; 11: e0148424.

14. Bruening T, Al-Khaled M. Stroke-Associated Pneumonia in Thrombolyzed Patients: Incidence and Outcome. Journal of Stroke and Cerebrovascular Diseases. 2014; 24: 17241729.

15. Dziedzic T, Pera J, Klimkowicz A, Turaj W, Slowik A, Rog TM, et al. Serum albumin level and nosocomial pneumonia in stroke patients. European Journal of Neurology . 2006; 13: 299-301.

16. Walter U, Kolbaskea S, Patejdla R, Steinhagena V, Abu-Mugheisiba M, Grossmann A, et al. Insular stroke is associated with acute sympathetic hyperactivation and immunodepression. European Journal of Neurology.2013; 20:153-159.

17. Fromm A, Waje-Andreassen U, Thomassen L, Naess H. Comparison between ischemic stroke patients $<50$ years and $\geq 50$ years admitted to a single centre: The Bergen Stroke Study. Stroke Research and Treatment.2011:183256.

18. Masrur S, Smith EE, Saver JL, Reeves MJ, Bhatt DL, Zhao X, et al. Dysphagia screening and hospital-acquired pneumonia in patients with acute ischemic stroke: findings from get with the guidelines-stroke. Journal of Stroke and Cerebrovascular Diseases.2013; 22:e301-e309.

19. Schwarz S, Al-Shajlawi F, Sick C, Meairs S, Hennerici MG. Effects of Prophylactic Antibiotic Therapy With Mezlocillin Plus Sulbactam on the Incidence and Height of Fever After Severe Acute Ischemic Stroke. Stroke.2008;39:1220-1227.

20. Kalra L, Irshad S, Hodsoll J, Simpson M, Gulliford G, Smithard D, et al, on behalf of the STROKE-INF InvestigatorsProphylactic antibiotics after acute stroke for reducing pneumonia in patients with dysphagia (STROKE-INF): a prospective, cluster-randomised, open-label, masked endpoint, controlled clinical trial. Lancet. 2015; 386: 1835-44.

21. Ran L, Khatibi NH, Qin X, Zhang JH. Proton Pump Inhibitor Prophylaxis Increases the Risk of Nosocomial Pneumonia in Patients with an Intracerebral Hemorrhagic Stroke. 
Intracerebral Hemorrhage Research, Acta Neurochirurgica Supplementum, 2011;111:435439.

22. Sreeraj K, Iype T, Madhavan N, Balan CS. Prevalence of Post stroke complications in south India-a descriptive study. International Journal of Pharmacy and Technology. 2012; 4:3859-3868.

23. Lam OL, McMillan AS, Samaranayake LP, Li LS, McGrath C. Randomized clinical trial of oral health promotion interventions among patients following stroke. Archives of Physical Medicine and Rehabilitation. 2013; 94:435-43.

24. Ingeman A, Andersen G, Hundborg HH, Svendsen ML and Johnsen SP. Processes of care and medical complications in patients with stroke. Stroke.2011; 42:167-172.

25. Marciniak C, Korutz AW, Lin E, Roth E, Welty L, Lovell L. Examination of selected clinical factors and medication use as risk factors for pneumonia during stroke rehabilitation: a case-control study. American Journal of Physical Medicine \& Rehabilitation.2009; 88:3038. 